\title{
ORGANIZATIONALLY-AGNOSTIC BUSINESS MODELING: A CASE STUDY
}

\author{
Sheila A. Cane, The MITRE Corporation, Virginia, USA \\ Carlos E. Martinez, The MITRE Corporation, Virginia, USA
}

\begin{abstract}
This paper presents a sample application of organizationally-agnostic business processes modeling to determine how business architecture can be made adaptable to organizational change. As-is business processes of a US Government agency were modeled based on existing documentation. This paper demonstrates the modeling process and describes how the results can be used to assist in examining organizational activity and information flows, and to easily document related organizational changes.

A US government organization had an urgent need to develop their business architecture. However, the leadership was concerned that once having done so, any organizational changes would be difficult to implement. This concern is understandable given that almost every organization is affected by continually changing political, operational, environmental, and technical (POET) factors. Enterprise Architecture (EA) methods can be tailored to solve this problem and enable the organization to change according to its needs. This paper shows how, in particular, activity and swim-lane models can be used to model the top-level operational processes in a way that enables organizational change. MITRE's work on this effort was provided under the sponsorship of the Department of Homeland Security. The work demonstrated in this paper was the result of the collaboration of The Homeland Security Systems Engineering \& Development Institute (HS SEDI) operated by the MITRE Corporation and DHS enterprise architecture personnel.
\end{abstract}

Having developed a generic methodology to model the business processes of an enterprise independent of its organizational structure, the authors wanted to demonstrate to validate its value by applying it to a subset of the organization. The sample application of the methodology is based on the organization's existing (As-Is) business processes as derived from the organization's existing documentation..

The analysis began with a review of existing documentation to initially describe the business processes of the agency. This principal source document described the responsibilities of each of the organizational subcomponents of the agency. To help interpret the contents of the existing planning document, the models were developed by a small team of EA and agency subject matter experts. Due to time and resource limitations, no attempt was made to verify the contents of the documentation with the specific organizations cited in the plan. Because of the sensitive nature of the particular organization's lines of business, all references to the organization, its activities, and its information products have been expressed only in generic terms. In this model, the organizational components are referred to as the Plans Division, the Operations Division, the Analysis Division, and an External Organization that supports the agency.

The existing documentation presented agency functions by organizational subcomponent. This construct is quite commonly used to prescribe the activities and outcomes for which each organizational component is responsible. However, since the objective of the methodology is to be organizationally-agnostic, this construct presented the first major challenge: that of identifying the overall business processes of the organization in common-language terms. Based on the review of the documentation, the core business of the subject agency could best be summed up in terms of five major activities:

- Plan and Organize. Determining who should do what, when, and where.

- Collect. Gathering information from disparate sources.

- Analyze Risks. Determining risks to other organizations based on the information collected. 


\section{Issues in Information Systems}

Volume 13, Issue 2, pp. 404-410, 2012

- Monitor. Performing continuous review of the operating environment.

- Share and Inform. Providing a broad range of information products to other organizations based on the activities it conducts.

Having agreed upon a set of core activities that describe the overall business of the agency the team began development of the organizationally-agnostic business model. As described in Martinez and Cane (2012), the authors chose the IDEF0 ${ }^{1}$ modeling technique to model the organization's activities, and swim-lane diagrams for the business processes. The model was developed using Microsoft Visio 2010 Professional Edition software. The Professional Edition was chosen because it supports IDEF0 modeling, albeit in a very rudimentary way that requires considerable manual review to ensure consistency among the models developed.

The model was developed starting at the top (A-0 or context) level, wherein all of the inputs, controls, outputs, and mechanisms (ICOMs) for the agency's core operational activities were defined. Figure 1 presents the A-0 diagram for the agency's core processes.

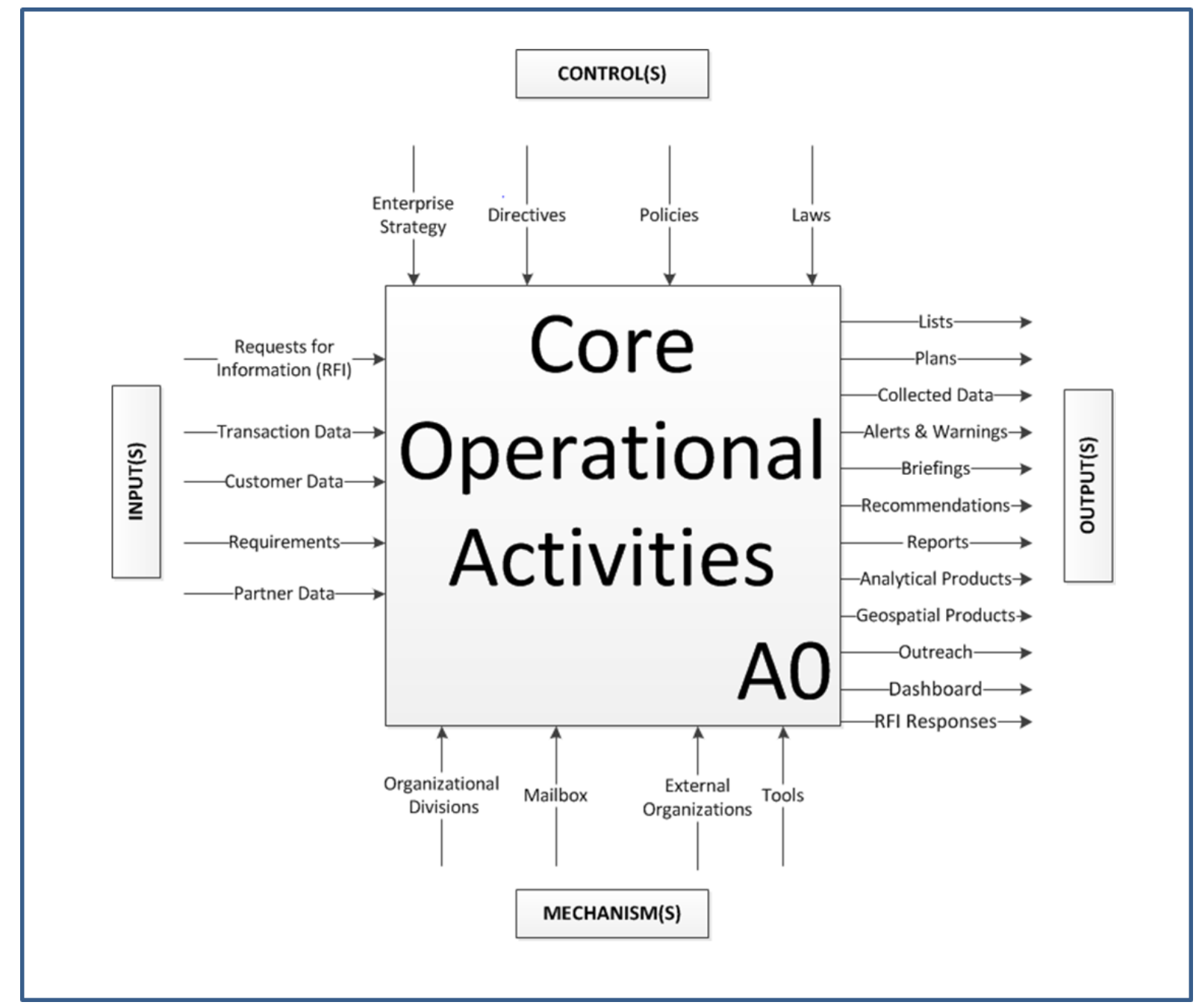

Figure 1. Top-Level (A-0) Agency Context Diagram

\footnotetext{
${ }^{1}$ Integrated DEFinition (IDEF) 0 is a standardized notation and approach for conducting business modeling.
} 


\section{Issues in Information Systems}

Volume 13, Issue 2, pp. 404-410, 2012

As can be seen from this model, the agency complies with higher-level enterprise strategies, directives, policies, and laws (the controls), to transform various sorts of data (transaction data, customer data, and partner agency data) in response to various requirements and specific requests for information (RFI), to produce a variety of outputs.

Among these outputs are:

- Planning documents such as operating plans and lists of product recipients

- Copies of the data it has collected and compiled

- Results of activities such as reports, geospatial and other analytical products, and briefings

- Alerts and warnings based on its monitoring of the environment

- Recommendations for action by other organizations or agencies

- Outreach to other organizations or agencies to share its collective knowledge and experiences

- Posting of information on a dashboard visible to higher levels of the enterprise

- Responses to RFIs

In support of the majority of its activities, the agency employs the three major organization divisions. However, it also draws support from some external organizations for specific capabilities that it does not organically possess. In addition, it uses a mailbox through which RFIs can be readily submitted and automated tools to conduct some of its analysis. Having defined the major core activities for the agency, the architects built the next level (A0) model to show the relationships among these activities. The A0 model is depicted in Figure 2. Note that due to limitations in the modeling tool, colors are used to illustrate linkages. Specifically, all ICOMs that originate or terminate external to the organization are typically depicted in black, unless there are multiple sources/destinations that make them hard to follow. Colors are also used to depict internal relationships. For example, Plans is colored red and Lists purple to show that they are outputs that serve as controls on other activities; Request Collection is colored green to show that it is an internal feedback to another activity; and Analytical Results and Situational Awareness are colored blue to show that they represent internal output-input relationships.

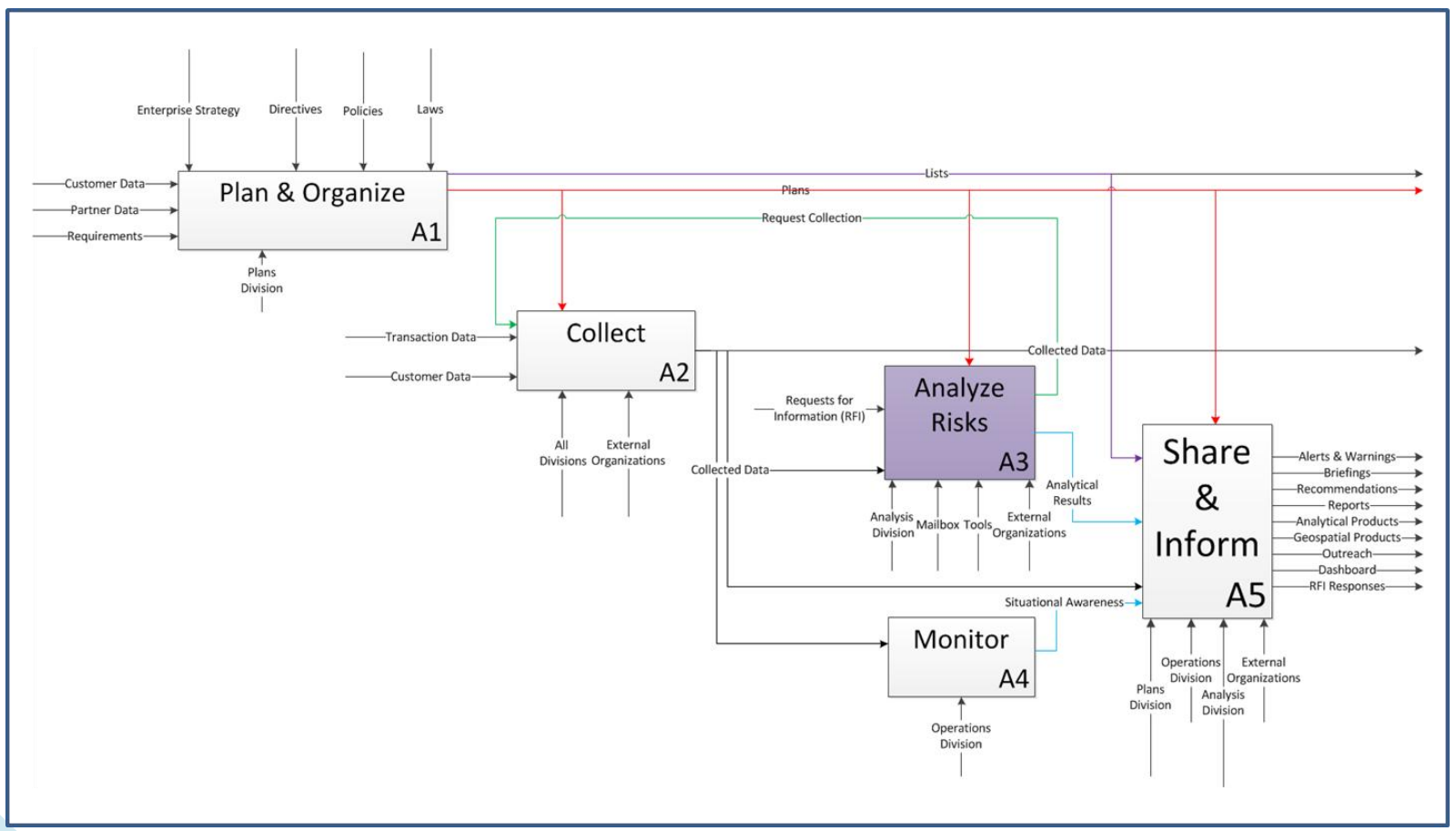

Figure 2. A0 Level, Major Agency Core Activities 


\section{Issues in Information Systems}

Volume 13, Issue 2, pp. 404-410, 2012

At the A0 level, the team started allocating organizations to the various core activities based on the statements in the agency's planning documentation. The authors examined the statements in the plan for each organization, and identified which of the major core activities best summarized the activities described for a particular organization. For example, the Monitor activity is the principal responsibility of the Operations Division. Similarly, the Plan and Organize activity is the principal responsibility of the Plans Division. However, the planning document indicated that more than one organization was involved in conducting most of the other activities. For example, each organizational element was responsible for some Share and Inform activities and all Divisions appear to Collect data. At this level of the model, one can begin to see interactions among the activities. For example, the plans developed by the Plans Division serve as guidance for the work done by the other divisions.

Since this was a proof-of-concept effort, only one activity, Analyze Risks, was selected for a more detailed examination, hence, the color highlighting it in Figure 2. The next-level decomposition of the Analyze Risks activity is presented in Figure 3.

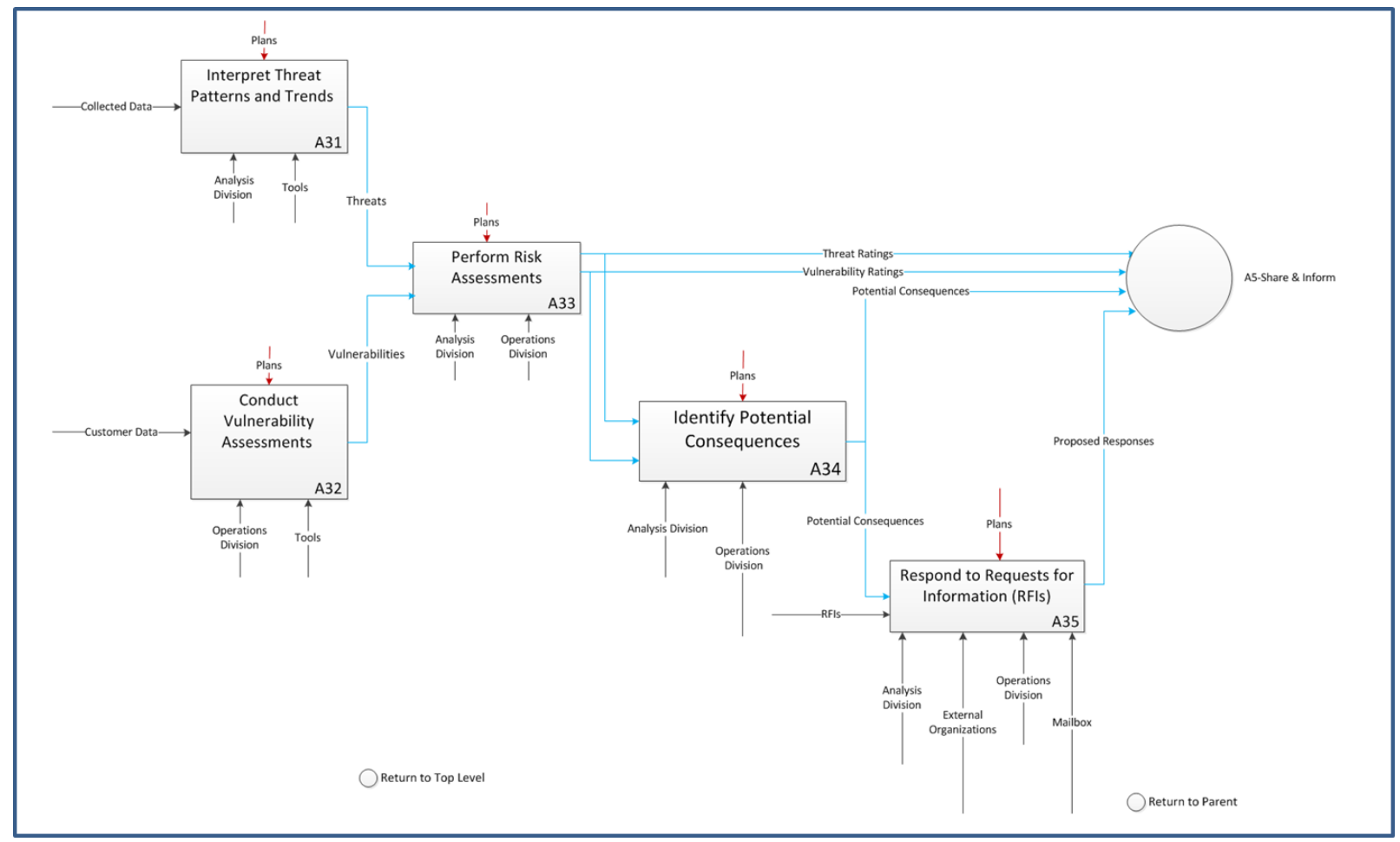

Figure 3. Activities Related to Analyze Risks

Development of this level required careful reading of the documentation and consultation with the agency's staff. For example, the Operations Division and the Analysis Division was described as responsible for conducting risk assessments. However, the two divisions actually perform complementary activities related to risk assessment. As shown by activities A31 and A32 in the diagram, the Analysis Division supports risk assessment by first examining collected data to identify threat patterns and trends. On the other hand, the Operations Division supports risk assessment by first examining customer data to identify vulnerabilities to threats. The activities of the two organizations come together in activity A33, Perform Risk Assessments, as specifically called out in the planning document. 


\section{Issues in Information Systems}

Volume 13, Issue 2, pp. 404-410, 2012

In keeping with the organizationally-agnostic business modeling approach, this activity was further decomposed to determine any duplication of effort between the two divisions, or if, in fact, each one did something different. Figure 4 presents the further decomposition of A33, Perform Risk Assessments.

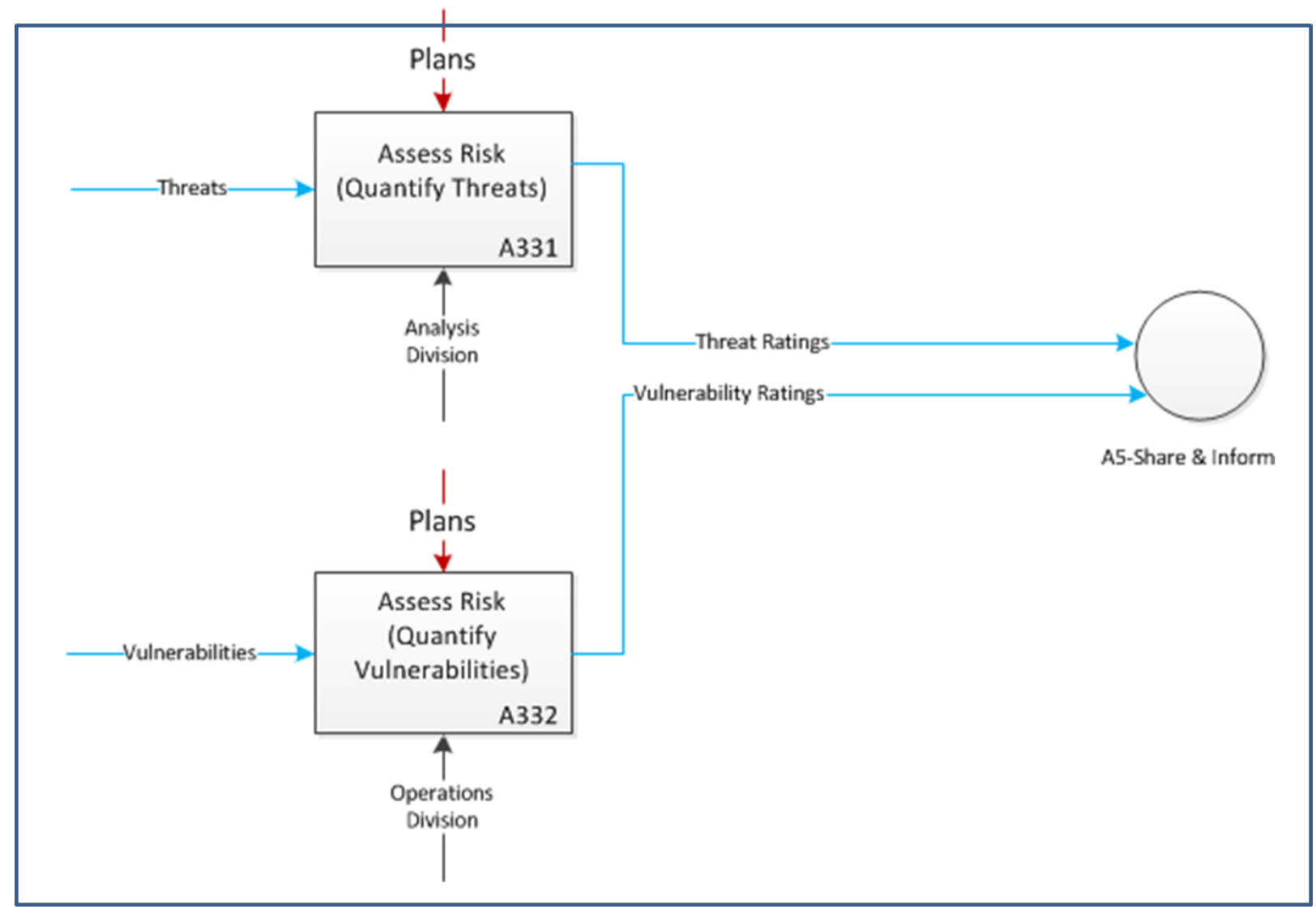

Figure 4. Further Decomposition of A33, Perform Risk Assessments

Closer examination of the documentation did not provide any explicit description of differences between the activities of the Analysis and Operations divisions. For each one, the specified activity was the same, Assess Risk, for which the specified output was a risk rating. Based on its discussions with the agency staff, the architects concluded that the only real difference between the two activities was that the Analysis Division was responsible for Assessing Risk by Quantifying Threats (converting Threats into Threat Ratings, while the Operations Division was responsible for Assessing Risk by Quantifying Vulnerabilities (converting Vulnerabilities into Vulnerability Ratings).

Again, because the model was developed only to demonstrate the process, no attempt was made to further decompose activities A34 and A35.

Figure 5 presents the full set of activities that were identified for this sample application in tree form. The activities highlighted in green represent the lowest (leaf-level) of the Analyze Risk activities. 


\section{Issues in Information Systems}

Volume 13, Issue 2, pp. 404-410, 2012

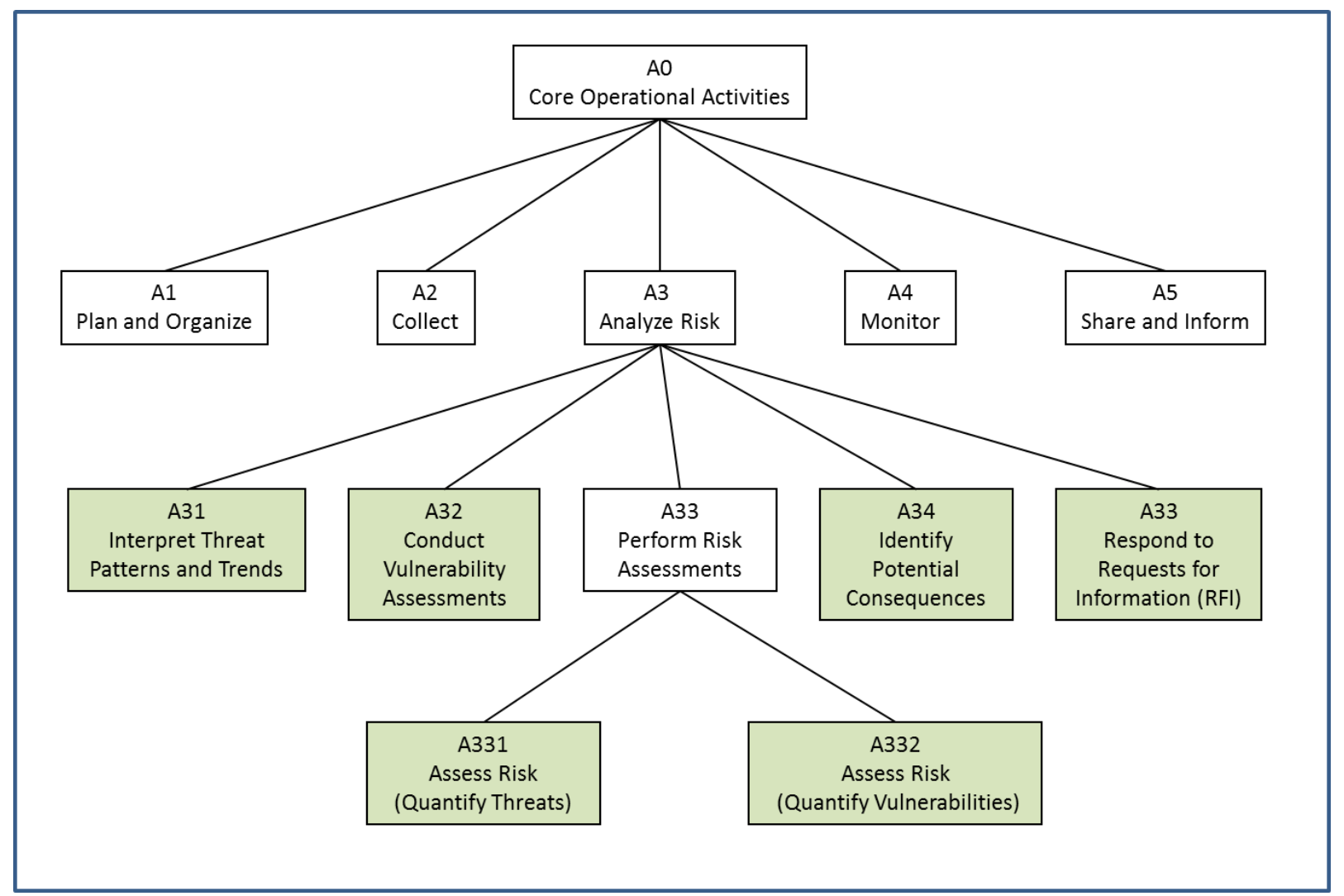

Figure 5. Lowest (Leaf-level) Analyze Risk Activities

These lowest (leaf level) activities (each performed by an individual organization) can be linked to show the sequential processes by which the organization produces the overall business results.

Based on the information captured in the IDEF0 activity models and by discussions with the sponsoring agency's staff, the information flows within and between the Divisions; were depicted as "threads" of information flows in the form of a swim-lane diagram, as depicted in Figure 6. 


\section{Issues in Information Systems}

Volume 13, Issue 2, pp. 404-410, 2012

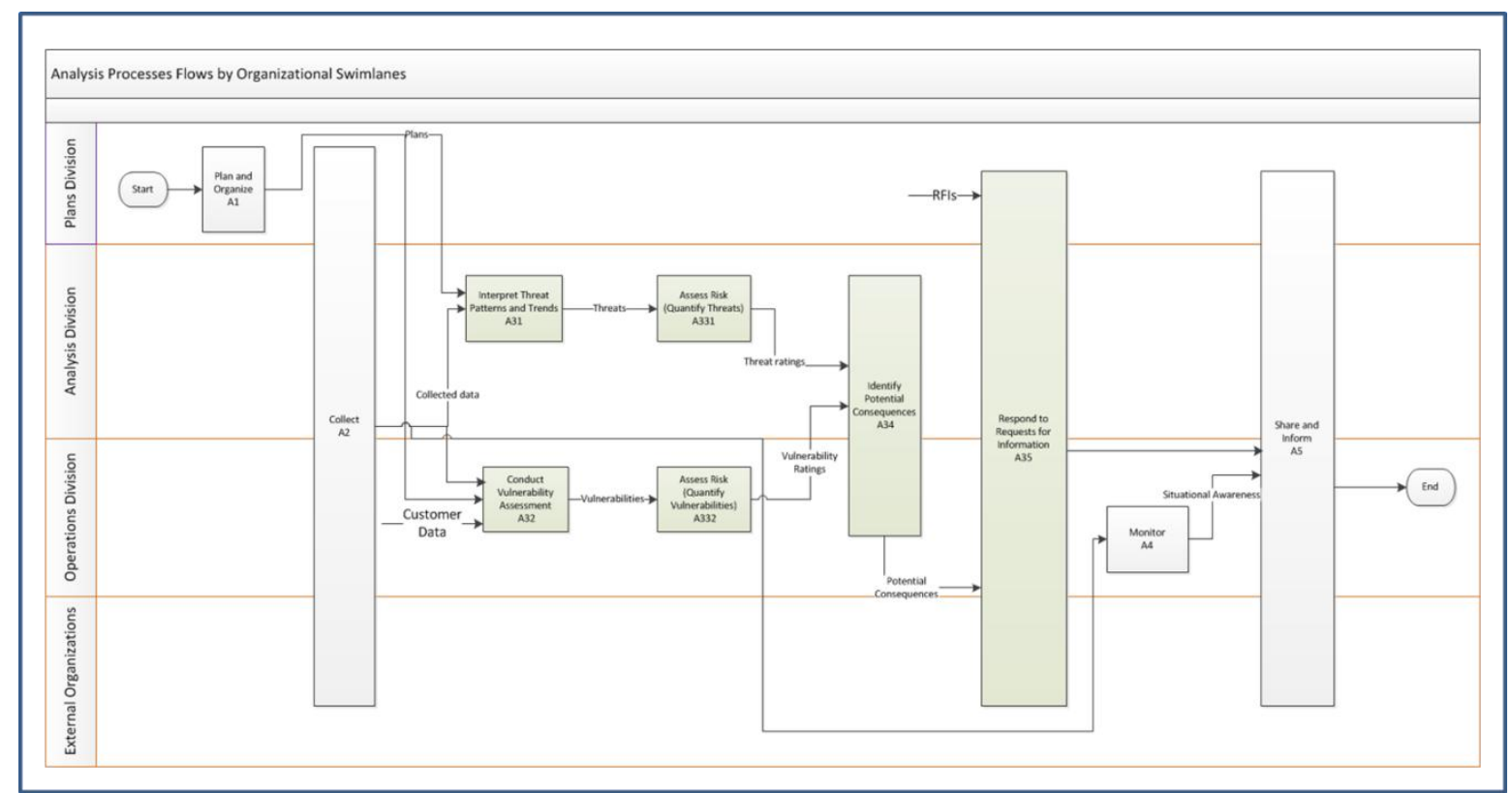

Figure 6. "Swim-Lanes" for the "Mechanism" Organizations to Show Information Flow

The Analyze Risk activities, highlighted in green, are presented within the context of the other core activities to show how they fit into an overall process for the agency.

As can be readily seen from the swim-lane diagram there are some activities depicted (A2-Collect, A34-Identify Potential Consequences, A35-Respond to Requests for Information, and A5-Share and Inform) that cut across multiple organizational lanes. This is because either the organizations conduct duplicate activities, or as is more likely, those activities have not yet been decomposed to a sufficient level to identify the particular organization responsible for conducting the activity. The only way to resolve the ambiguity will be to conduct more detailed analysis to determine who is really responsible for conducting the activity (for the As-Is situation), or who should be (the To-Be model).

As simple as this organizationally-agnostic activity modeling exercise has been, the authors believe that it offers opportunities for organizational realignment. For example, as depicted in Figure 6, the Analysis and Operations divisions appear to be conducting parallel sets of activities, some of which are so similar (i.e., A331 and A332) that they could possibly be combined and given to just one of the two organizations to perform. By further decomposing the activities that cut across several swim lanes, other potential opportunities for realigning organizational responsibilities against one consistent activity model may also be discovered.

In conclusion, through this sample real-world application, the efficacy of organizationally-agnostic activity modeling through IDEF0 and swim-lane modeling of the lowest level hierarchy activities is shown. More importantly, when combined with a visual presentation of the result, as demonstrated by the swim-lane diagram, the models readily point out potential opportunities for organizational realignment of responsibilities. When organizational changes are made, it is a simple process to update the IDEF0 models and to move the activities to the new swim-lane. This method enables continuous organizational improvement.

\section{ACKNOWLEDGMENTS}

This paper was written by the MITRE Corporation, in collaboration with and funding from the Deputy Assistant Secretary of Homeland Security, Cybersecurity \& Communications (CS\&C), through the Department of Homeland Security FFRDC (Homeland Security Systems Engineering and Development Institute (HS SEDI)) under contract \# HSHQDC-09-D-00001. 